\title{
Análisis del marco legal ambiental aplicable a la protección y conservación de humedales urbanos de la ciudad de Pilar
}

Isabel Benítez de Candia

ibenitezdecandia@gmail.com

Marcelo Candia Acosta

marcelocandia.acos@gmail.com

Universidad Nacional de Pilar

\section{RESUMEN}

Se aborda el análisis del marco legal ambiental aplicable a la protección y conservación de cauces hídricos urbanos de la ciudad de Pilar, Departamento de Neembucú, ubicada en una zona de humedales, en la que es recurrente la problemática vinculada a inundaciones de origen pluvial. Se describe la tendencia de una política ambiental proteccionista a nivel nacional, no obstante, a nivel local se observan debilidades en la protección y conservación de los humedales, por falta de regulación en la construcción de canales, entubamientos y terraplenes, ocupación de áreas inundables y de zonas de amortiguamiento, disposición final de residuos y gestión integral de los recursos hídricos; obras o actividades que deben ser contemplados en la planificación urbana. Finalmente se analizan estudios técnicos presentados en el marco de la ejecución de obras consideradas de impacto relevante sobre los cauces hídricos y conforme a los hallazgos se plantean algunas propuestas que permiten orientar la política urbana local hacia las exigencias legales ambientales.

Palabras clave: legislación ambiental, humedales urbanos, planificación urbana, Ñeembucú. 


\title{
Analysis of the environmental legal framework applicable to the protection and conservation of urban wetlands in the city of Pilar
}

\begin{abstract}
We address the analysis of the environmental legal framework applicable to the protection and conservation of urban watercourses in the city of Pilar, Department of Neembucú, located in a wetland area, where recurrent problems related to floods of pluvial origin. The trend of a protectionist environmental policy at national level is described, however, at the local level weaknesses in the protection and conservation of wetlands are observed, due to lack of regulation in the construction of canals, intubations and embankments, occupation of flooded areas and of buffer zones, final waste disposal and integrated management of water resources; works or activities that should be contemplated in urban planning. Finally, technical studies presented in the framework of the execution of works considered of relevant impact on the water channels are analyzed and according to the findings some proposals are put forward that allow to guide local urban policy towards the environmental legal requirements.
\end{abstract}

Keywords: environmental legislation, urban wetlands, urban planning, Neembucú

Artículo recibido: 03 nov. 2020

Aceptado para publicación: 07 dic. 2020

Correspondencia ibenitez@aplicadas.edu.py Conflictos de Interés: Ninguna que declarar 


\section{INTRODUCCIÓN}

Ñeembucú, duodécimo departamento del Paraguay, posee un sistema ambiental muy frágil, en el sentido del mantenimiento del equilibrio ambiental, en su mayor parte constituido por humedales que abarcan una superficie de más de 1 millón de hectáreas de reservas de agua constituidos por ríos, arroyos, aguadas, riachos, esteros, lagunas y nacientes. El área de estudio se circunscribe a la ciudad de Pilar, capital del Departamento de Ñeembucú, con una superficie total de 38.227 hectáreas.

Pilar, un área con características de anegabilidad e inundación, está rodeada de muros de contención tipo terraplén, para evitar inundaciones por los desbordes del río Paraguay y de los arroyos Ñeembucú, San Lorenzo y otros arroyos de menor cauce como el Havõ. Dentro del área de estudio, las inundaciones se producen tanto por la localización de zonas urbanas en áreas bajas, como por la modificación del comportamiento del sistema hídrico por efecto de nuevos asentamientos, lo que produce que el agua de lluvia tenga dificultades para drenar hacia el río Paraguay y arroyo el Ñeembucú.

La Ley No 3239/2007 De Los Recursos Hídricos Del Paraguay reconoce las funciones de los humedales relacionadas con el ciclo hidrológico que son las siguientes: 1. El almacenamiento de agua: retención de aguas superficiales, regulación de caudales, mitigación de las inundaciones, recarga de aguas subterráneas y descarga de aguas subterráneas. 2. El control de la calidad del agua: purificación del agua, retención de nutrientes, retención de sedimentos y retención de agentes contaminantes. 3. La regulación del clima local: estabilización del clima local, regulación de las precipitaciones y la temperatura y la reducción de la evapotranspiración. La protección y, en caso necesario, la restauración de los humedales será uno de los medios de mantener el suministro de agua para diversos usos del ser humano. (Art. 31)

Actualmente se registran eventos climáticos atípicos y según reportes técnicos de la Dirección de Riesgos de Municipalidad de Pilar, en enero del 2017 el nivel de agua caída fue de 116 mm; en febrero 133,7 mm; en marzo 107,8 mm; en abril se llegó a los 515 mm y en lo que va de mayo se reportan más de $165 \mathrm{~mm}$.

El Plan de Desarrollo Sustentable de Pilar (2016) refiere que, desde el punto de vista físico natural, las inundaciones en Pilar reconocen dos detonantes: lluvias torrenciales (que colmatan la capacidad instalada de los desagües pluviales y provocan anegamientos y desbordes interiores de los arroyos) y el efecto de falta de capacidad de bombeo y falta 
de reservorios suficientes Estas condiciones, que pueden presentarse en forma independiente o ser concurrentes, son el punto de partida para una serie de sucesos encadenados, donde los factores de control están íntimamente asociados a la topografía del área y a las formas en que se ha desarrollado la urbanización del territorio.

El trabajo tiene como objetivo principal describir las condiciones de los humedales urbanos de la ciudad de Pilar y determinar la existencia de regulación ambiental local conforme las exigencias de la política ambiental nacional. Se propone como objetivos específicos analizar las disposiciones legales sobre protección de cauces hídricos urbanos en el ámbito nacional y regional, determinar las obras o actividades de impacto ambiental relevante sobre los cauces urbanos y analizar los estudios técnicos presentados en el marco de ejecución de las mismas.

El propósito de la investigación es proporcionar a los entes reguladores locales los lineamientos generales para la adopción de mecanismos de protección integral de los cauces hídricos que conforman los humedales urbanos de la ciudad de Pilar.

\section{MATERIALES Y MÉTODOS}

El estudio, realizado en el año 2017, responde al diseño descriptivo, con aplicación del método cualitativo donde se registra el análisis de las condiciones de los humedales urbanos de la ciudad de Pilar en materia de protección y conservación, para la comprensión del fenómeno de estudio considerado desde sus aspectos particulares. Para ello, se estudian las disposiciones legales sobre protección de cauces hídricos urbanos, obras o actividades de impacto ambiental relevante sobre estos cauces y los estudios técnicos para su ejecución.

El universo está determinado por la legislación positiva nacional, la población abarca las leyes ambientales y las leyes que establecen la autoridad de aplicación de disposiciones ambientales. La muestra se circunscribe a disposiciones legales de protección de los cauces hídricos urbanos de la ciudad de Pilar, departamento de Ñeembucú. Los datos son obtenidos por las técnicas análisis documental e informante clave.

Para el análisis de las disposiciones legales sobre protección de cauces hídricos urbanos en el ámbito nacional, departamental y municipal, primeramente se procedió a identificar y describir de manera general, las leyes que componen el derecho positivo ambiental, en el orden de prelación enunciado en el Art. 137 de la Constitución Nacional, de modo a establecer el marco normativo nacional en el que se sustenta la política ambiental para 
exigir la descentralización de la protección de recursos naturales a través de la regulación ambiental local.

Una vez identificada las principales leyes ambientales, se examinaron aquellas legislaciones que atribuyen funciones de autoridad de aplicación de esas leyes en el ámbito local. En tal sentido, se tomó a la Ley $\mathrm{N}^{\circ} 1.561 / 00$ a fin de determinar las facultades de la Secretaría del Ambiente para regular la protección de recursos hídricos específicos y toda actividad susceptible de alterarlo, para lo cual se recurrió al estudio de la Ley N²94/93 de Evaluación de Impacto Ambiental.

Se utilizó además como unidad de análisis la Ley $N^{\circ}$ 426/94 Que establece la Carta Orgánica del Gobierno Departamental, de modo a vincular los deberes y atribuciones del Gobierno Departamental con la efectiva protección y conservación de recursos naturales, específicamente los humedales urbanos. Asimismo, se abordó la N³966/10 Orgánica Municipal y se procedió a la revisión y análisis de los artículos que otorgan funciones regulatorias en materia de planificación, urbanismo y ordenamiento territorial, así como en materia de ambiente.

Para determinar las obras o actividades de impacto ambiental relevante sobre los humedales urbanos, se recurrió a los archivos de la Junta Municipal de Pilar, solicitando documentos regulatorios de planificación, urbanismo y ordenamiento territorial.

Finalmente, se accede a los archivos de la SEAM (Secretaría del Ambiente) en relación a documentaciones de obras y actividades encaradas en Pilar, en el marco de la Ley $\mathrm{N}^{\circ}$ 294/93, además de publicaciones de estudios técnicos relacionados a los humedales de Pilar, para completar el análisis documental.

\section{RESULTADOS Y DISCUSIÓN}

Antes de enunciar los hallazgos, conviene aclarar el alcance del término política ambiental. "La Política Ambiental es el conjunto de objetivos, principios, criterios y orientaciones generales para la protección del ambiente de una sociedad, con el fin de garantizar la sustentabilidad del desarrollo para las generaciones actuales y futuras". (SEAM: Política Ambiental Nacional). Entre los instrumentos que pone en marcha esta política se tiene el desarrollo del marco legal, el ordenamiento ambiental del territorio, la evaluación del impacto ambiental, la auditoría ambiental, el sistema de vigilancia y control ambiental, entre otros. 
La política se organiza a nivel nacional, departamental y municipal; busca descentralizar la gestión ambiental y el fortalecimiento de la capacidad de gestión local, mediante la participación social.

El derecho positivo ambiental se compone de innumerables disposiciones legales y normativas en orden de prelación. Primeramente, de la Constitución Nacional (1992) en su Capítulo I, Sección II “Del Medio Ambiente”, establece que los conceptos de ambiente saludable y equilibrio ecológico son derechos fundamentales de todos los habitantes de la República, al tiempo de consagrar como principios constitucionales la preservación, conservación, recomposición y mejoramiento del ambiente. La Constitución Nacional otorga protección al medio ambiente ${ }^{1}$ y establece el derecho de las personas de vivir en un ambiente saludable ${ }^{2}$.

El mandato constitucional para la elaboración del marco legal interno en materia ambiental establece los siguientes delineamientos: i) prevenir, regulando las actividades susceptibles de alterar el ambiente y restringiendo o prohibiendo actividades que sean consideradas peligrosas; ii) sancionar, tipificando delitos ecológicos e imponiendo las sanciones penales correspondientes; y iii) compensar e indemnizar por el daño causado. Por otra parte, establece el derecho a la defensa de los intereses difusos ${ }^{3}$, por el que "toda persona, individual o colectivamente, podrá formular a las autoridades públicas, entre otros reclamos, medidas para la defensa del ambiente, de la integridad del hábitat y de la salubridad pública...”. También establece la obligación del Estado de regular por ley todas las actividades susceptibles de producir alteración ambiental y la obligación de recomponer e indemnizar todo daño causado al ambiente.

En el segundo nivel, el derecho positivo ambiental se compone de los convenios, tratados y acuerdos internacionales, ratificados por ley de la república. Entre ellos la Convención sobre Diversidad Biológica (CDB), la Convención Marco sobre Cambio Climático (CMNUCC), la Convención contra la Desertificación y Sequía, la Convención Ramsar, entre otras. La nómina no es taxativa, ya que se mencionan las que se consideran fundamentales para el estudio.

Ley N $N^{o} 350 / 94$ "Que aprueba la Convención relativa a los humedales de importancia internacional, especialmente como hábitat de aves acuáticas", define como humedales las

\footnotetext{
${ }^{1}$ Constitución Nacional, Art. 8.

${ }^{2}$ Constitución Nacional, Art. 7.

${ }^{3}$ Constitución Nacional, Art. 38.
} 
extensiones de marismas, pantanos y turberas, o superficies cubiertas de aguas, sean éstas de régimen natural o artificial, permanentes o temporales, estancadas o corrientes, dulces, salobres o saladas, incluidas las extensiones de agua marina cuya profundidad en marea baja no exceda de seis metros (Art. 1). Establece que "Cada Parte contratante designará humedales idóneos de su territorio para ser incluidos en la lista de humedales de importancia internacional...” (Art. 2) y que “...deberán elaborar y aplicar su planificación de forma que favorezca la conservación de los humedales incluidos en la lista y, en la medida de lo posible, en uso racional de los humedales de su territorio" (Art. 3). No se dispone de planificación para la conservación de los humedales de Ñeembucú, y por ende de Pilar.

En el tercer nivel de jerarquía, se ubican las leyes nacionales que regulan materias ambientales y por último, las disposiciones de menor jerarquía. Tal es el caso de las Resoluciones y Decretos que reglamentan las leyes y que por una cuestión práctica se irán citando junto con las leyes nacionales.

La Ley $\mathrm{N}^{0} 1.160 / 97$. “Código Penal”, que tipifica los delitos ecológicos e impone las sanciones penales a los infractores. En el Título III "Hechos punibles contra la seguridad de la vida y de la integridad física de las personas". Capítulo I Hechos Punibles contra las Bases Naturales de la Vida Humana, establece seis tipos penales, entre los que se encuentra el Ensuciamiento y alteración de las aguas, subterráneas y superficiales, riberas y cauces, castigando con pena privativa de libertad o multa la acción, la tentativa y la omisión (Art. 197).

Además de la ley penal general, se cuenta con una ley especial, la ley No 716/96 "Que sanciona los delitos contra el medio ambiente”. En la opinión de Merlo (2004) esta legislación penal responde a situaciones que han conmovido a la comunidad, razón por la que de manera intempestiva, los legisladores tipificaron diversidad de conductas, inclusive algunas cuya sanción es más propio de autoridades administrativas, por lo que este autor considera que es excesiva la tipificación de las conductas penales.

La ley que regula las actividades susceptibles de alterar el ambiente y restringe o prohíbe actividades que sean consideradas peligrosas es la $N^{\circ}$ 294/93 de Evaluación de Impacto Ambiental, reglamentado por el Decreto $N^{\circ} 453 / 2013$ y el Decreto № 954/2013 que modifica y amplía los artículos y el anexo del Decreto 453/2013. El principio 
contaminador-pagador se halla incorporado en esta ley de carácter administrativo y responde al mandato constitucional de compensar e indemnizar por el daño causado.

La Ley N ${ }^{\circ}$ 294/93 declara obligatoria la Evaluación de Impacto Ambiental y define este término como "toda modificación del medio ambiente provocada por obras o actividades humanas que tengan, como consecuencia positiva o negativa, directa o indirecta, afectar la vida en general, la biodiversidad, la calidad o una cantidad significativa de los recursos naturales o ambientales y su aprovechamiento, el bienestar, la salud, la seguridad personal, los hábitos y costumbres, el patrimonio cultural o los medios de vida legítimos”. (Art.1). El Artículo $7^{\circ}$ lista los proyectos de obras o actividades públicas o privadas que requieren de Evaluación de Impacto Ambiental entre los que se encuentran las urbanizaciones, sus planes directores y reguladores, la construcción y operación de conductos de agua, la disposición final de residuos urbanos, las obras viales y cualquier otra obra o actividad que por sus dimensiones o intensidad sea susceptible de causar impactos ambientales; por lo que la lista no taxativa.

La Ley $\mathrm{N}^{\circ} 1.561 / 00$ que crea el "Sistema Nacional del Ambiente, el Consejo Nacional del Ambiente y la Secretaría del Ambiente", designa a la Secretaría del Ambiente como autoridad de aplicación de varias leyes ambientales, entre ellas, la Ley $N^{\circ}$ 294/93 De Evaluación de Impacto Ambiental. La SEAM tiene facultades para regular la protección de recursos hídricos específicos.

Un importante avance constituye la Resolución $N^{\circ} 1076 / 11$ por lo que la Secretaría del Ambiente declaró de Interés Ambiental Nacional los humedales del pantanal del departamento de Ñeembucú. El considerando de la resolución expresa que estos humedales son parte del Sistema de Humedales del Valle Central de la Cuenca del Plata, mayor sistema de humedales del Planeta, responsable de la regulación de los caudales de los ríos Paraguay y Paraná, de la mitigación de los impactos de sequías y de las inundaciones; de la producción de agua dulce de alta calidad; de la producción de alimentos sanos para millones de personas; que el mismo constituye uno de los mayores reservorios de biodiversidad y que el Departamento de Neembucú está casi totalmente incluido en este sistema de humedales. El Art. 1 dispone: "Declarar de Interés Ambiental Nacional a los humedales del Pantanal del Departamento de Neembucú, ubicados en la región Sur Oeste del Paraguay, por su importancia para la producción del agua; la conservación de la biodiversidad y la calidad ambiental en el territorio del Paraguay, 
así como la promoción de la declaración como sitio Ramsar, a los humedales de importancia internacional en toda su extensión."

El próximo paso requerido es la adopción de medidas de carácter preventivo para la protección de los recursos hídricos, en disposiciones que tengan fuerza de ley, donde la autoridad ejecutiva aplique y los organismos especializados estudien las problemáticas, propongan medidas destinadas a reducir los peligros que pueda presentar la ejecución de ciertos proyectos, a reparar los daños causados por ellos, etc.

La Ley No 3239/2007 De Los Recursos Hídricos del Paraguay; tiene por objeto regular la gestión sustentable e integral de todas las aguas, en cuyo Artículo $9^{\circ}$.- establece " $E l$ manejo de los recursos hídricos en el Paraguay contará con un Plan Nacional de Recursos Hídricos, que será elaborado con base en la Política Nacional de los recursos hídricos. El Plan Nacional de Recursos Hídricos será actualizado permanente y sistemáticamente". Esta ley cede prevalencia ante otras normas legales que tiendan a prevenir la ocurrencia de daños al ambiente (Art. 24). Según la misma ley, la SEAM es la responsable de determinar el caudal ambiental de todos los cursos hídricos del país, la delimitación de las zonas de recarga de los acuíferos, el establecimiento de áreas restringidas a la utilización de las aguas subterráneas. (Art. 26)

Por Resolución N 170/06 la SEAM aprueba la reglamentación del Consejo de Aguas por Cuencas Hídricas y designa a la Dirección General de Protección y Conservación de Recursos Hídricos como órgano ejecutivo, gestor y coordinador del Consejo de Aguas para la Gestión de Recursos Hídricos. En este sentido, cabe mencionar que no se ha encontrado estudio alguno de esta entidad reguladora, que determine el caudal ambiental de los cursos hídricos de Pilar, ni tampoco establecimiento de restricciones en el uso de aguas subterráneas en el área de estudio.

Tharme expresa que el caudal ambiental establece cuánto del régimen hidrológico natural de un río debería seguir fluyendo aguas abajo y hacia la planicie de inundación para mantener los valores característicos del ecosistema (UNESCO, 2014).

Chamorro y otros (2017), realizaron un estudio morfométrico para la identificación y caracterización del área de drenaje de la cuidad de Pilar, aplicando herramientas del programa ArcGIS. El estudio, toma como referencia el Proyecto para la prevención de inundaciones por lluvia en la ciudad de Pilar departamento de Ñeembucú - Memorias de Ingeniería. Estudios topográficos cartográficos, realizados en 2000 (líneas de contorno) 
y aporta datos concluyentes sobre la delimitación de la cuenca urbana, definición de la red de drenaje y cálculo de algunas variables morfométricas e hidrológicas. Este análisis morfométrico constituye un aporte muy importante en la determinación de caudales máximos y mínimos en la cuenca urbana de Pilar.

La Ley No 3239/2007 establece que la conservación y manejo de los humedales requerirá de los conceptos siguientes: a) La necesidad de desarrollar su uso sustentable. b) Bajo la perspectiva de un enfoque integrado. c) El desarrollo de Planes de Manejo. (Art. 30). Pilar y más aún el departamento de Neembucú no cuentan con un instrumento legal que impida, por ejemplo, la agricultura a gran escala, u otras actividades que amenacen la conservación y manejo de los humedales. La utilización de los cauces hídricos y/o el vertido a éstos están sujetos a la concesión de permiso (Art. 32).

La Ley $\mathrm{N}^{\circ}$ 1183/85 Código Civil, tutela los cursos de aguas para evitar su deterioro y contaminación. La Ley $\mathrm{N}^{\circ}$ 2559/05 que modifica el artículo 1898 inciso b) del Código Civil amplía la protección abarcando a las aguas subterráneas entre los bienes de dominio público del Estado. Por su parte, la Ley N 836/80 Código Sanitario, regula las funciones del Estado en lo relativo al cuidado integral de la salud del pueblo y los derechos y obligaciones de las personas en la materia.

La Ley N 426/94 "Que establece la Carta Orgánica del Gobierno Departamental”, enuncia entre los deberes y atribuciones del Gobierno Departamental: Artículo 16.- inc. b) Coordinar planes, programas y proyectos con las Municipalidades del Departamento y cooperar con ellas cuando éstas la soliciten; y k) Adoptar medidas para la preservación... del medio ambiente y de los recursos naturales del Departamento. Dentro del apartado "De los planes de inversión", el Artículo 45.- establece que "Son planes de inversión los relacionados con: f) La conservación, preservación y recuperación del ambiente y de los recursos naturales. No se evidenció proyecto alguno, que implique coordinación entre los gobiernos departamental y municipal, en materia ambiental.

La Junta Departamental de Neembucú, por Resolución N 15/2011 declara de Interés Departamental la conservación ambiental y el manejo sustentable de los recursos naturales que componen el complejo de humedales del Departamento de Neembucú, a pedido de la Unión de Organizaciones de Ciudadanos del Ñeembucú, además de exhortar a las instituciones educativas a implementar con mayor énfasis la formación de conocimientos, valores y conductas en educación ambiental a sus educandos. La 
Declaración $N^{\circ}$ 02/2014 Por la cual declara al Departamento de Neembucú zona ambientalmente sustentable y libre de toda contaminación nuclear, a petición de miembros de la organización "Ciudadanos por la Vida", nuevamente nace por la preocupación de la sociedad civil organizada, ante la inminente instalación de planta nuclear en la provincia argentina de Formosa, que comparte frontera con el departamento de Ñeembucú.

La Ley N³966/10 Ley Orgánica Municipal dispone en su Artículo 12 entre las funciones Municipales: 1. En materia de planificación, urbanismo y ordenamiento territorial:

a. "la planificación del municipio, a través del Plan de Desarrollo Sustentable y del Plan de Ordenamiento Urbano y Territorial;". El Plan de Desarrollo Sustentable de Pilar (2016), elaborado por el Consejo de Desarrollo Municipal, con la participación del Comité de Emergencia Distrital, el Ejecutivo Municipal, representantes de instituciones públicas y privadas y de la ciudadanía en general; propone estrategias tendientes a lograr la implementación de acciones para el mejoramiento sostenido de la calidad de vida de la población de la ciudad de Pilar. En este documento se propone, dentro del eje Planificación y Gestión Municipal, la determinación municipal del dominio hídrico de aguas subterráneas, su río y arroyos, así como el mantenimiento del cauce ecológico del arroyo Ñeembucú.

En relación al Plan de ordenamiento Urbano y Territorial, la municipalidad de Pilar no cuenta con dicho instrumento, por lo que es difícil determinar la existencia de una política local que oriente el uso y ocupación territorial en el área urbana, así como la prevención de los riesgos de desastre, propios de los ámbitos urbanos. Si bien dispone de una Ordenanza que establece el "Código de Edificación de la Ciudad de Pilar", aprobada por Resolución $N^{\circ} 145 / 2005$, ésta regula trámites para iniciar obras edilicias como el pago de arancel e inspección, así como las especificaciones técnicas atinentes a la ejecución de la misma: instalaciones previas, excavaciones, cimientos, muros, fachadas, entre otras. No contempla regulación en la construcción de canales, entubamientos y terraplenes, adoquinados de calles, entre otras construcciones que constituyen obstáculos al escurrimiento de las aguas en sus cauces naturales y su posterior drenaje en río y arroyos. c. "la reglamentación y fiscalización del régimen de uso y ocupación del suelo;" No se encontraron normativas que regulen de manera específica la ocupación de inmuebles ubicadas en causes hídricos internos y zonas de amortiguamiento. La franja de dominio 
de la margen izquierda de la desembocadura del Arroyo San Lorenzo al río Paraguay, que se encuentre ocupado por viviendas.

Chocat (1997) destaca los impactos de la urbanización sobre el ciclo del agua entre las que menciona la impermeabilización del suelo, la aceleración de los escurrimientos, la construcción de obstáculos al escurrimiento, la artificialización de las acequias, arroyos y ríos en áreas urbanas y la contaminación de los medios receptores.

De las entrevistas a informantes clave, se evidencia la ausencia de instrumentos, tanto legales como técnicos, que permitan primeramente identificar los cursos de zonas anegadas y cursos de fuente semisurgente, arroyos, canales naturales de desagüe pluvial y reservorios, para su posterior protección y conservación. Según sus manifestaciones: "Los mapas con que cuenta el municipio son desactualizados, muestran supuestos hídricos como los denominados mandijurandy (zona de la terminal actual), laguna Coronel, laguna Gadea, Bado Ñu entre otros”, “...no hay protección legal de los cursos de agua. La Universidad Nacional de Pilar tiene identificado tres arroyos que parten de una fuente semisurgente (zona terminal). Uno de ellos se llama arroyo Havõ, los otros dos no tienen nombre pero lo identificamos por NF y VP". "Desde el municipio se trabaja en la planificación de acciones de prevención de riesgos y mitigación de los efectos causados por las inundaciones pluviales. En ese contexto se han encarado trabajos técnicos conjuntos, convocando a expertos del área de ingeniería, en el marco de búsquedas de solución definitiva de defensa costera".

d. "la reglamentación y fiscalización del régimen de loteamiento inmobiliario.", concordante con el Art. 248. de la misma ley: "Ubicación de las fracciones públicas: Es atribución de la Junta Municipal la aprobación de fraccionamiento de inmuebles. Si éstos son destinados a urbanización, requieren de un estudio de impacto ambiental.

El Relatorio de Impacto Ambiental (RIMA) presentado por la Inmobiliaria Don Quintín S.A. para el proyecto de loteamiento de lugar denominado Laguna Gadea, señala como impactos directos el aumento de la impermeabilización localizada del suelo a causa de la compactación de las calles y la formación de canales con peligro de crear sectores de agua estancada. Propone como medida de mitigación conservar en buen estado las cunetas y zanjas de drenaje, la construcción de canales de desagote a los lados de las calles, además de prever la colocación de áreas de disposición de residuos en la zona a lotear. Sin embargo, en el Plan de Monitoreo no se especifican actividades relacionadas al 
mantenimiento de canales de drenaje. La Junta Municipal de Pilar aprueba el fraccionamiento a través de la Resolución $N^{\circ} 245 / 2016$. No se menciona el ente o persona responsable de verificar el cumplimiento de las propuestas de mitigación planteadas. Tampoco hay datos concluyentes que permitan afirmar que el Municipio de Pilar realiza seguimiento alguno.

En materia de infraestructura pública y servicios, la Ley N 3966/10 Orgánica Municipal dispone en su Artículo 12: b. "construcción y mantenimiento de los sistemas de desagüe pluvial del municipio;”. 4. En materia de ambiente: “a. La preservación, conservación, recomposición y mejoramiento de los recursos naturales significativos; b. la regulación y fiscalización de estándares y patrones que garanticen la calidad ambiental del municipio;" “c. la fiscalización del cumplimiento de las normas ambientales nacionales, previo convenio con las autoridades nacionales competentes; $d$. el establecimiento de un régimen local de servidumbre y de delimitación de las riberas de los ríos, lagos y arroyos."

Dentro de sus potestades (Art. 15) las municipalidades podrán: a. dictar y ejecutar las ordenanzas, reglamentos y resoluciones; i) aplicar sanciones por comisión de faltas;".

El Proyecto Estudios de Ingeniería para el Acceso Vial al Puerto de Pilar (2014), proyecto de circunvalación que contempla la construcción de 13,68 km de pavimento, para el acceso al Puerto de la Administración Nacional de Navegación y Puertos (ANNP) de la ciudad de Pilar. Este contempla la realización de obras de drenaje: "Comprende la construcción de puentes; alcantarillas tubulares y celulares de hormigón, y cunetas, a fin de garantizar el normal escurrimiento de las aguas, y restituir los drenajes naturales, además de la intersección y conducción de napas freáticas subterráneas, por medio de drenes subterráneos.” (RIMA, pág. 9). Los estudios hidrológicos establecen las características de escurrimiento superficial de las cuencas hidrográficas interceptadas por los trazados propuestos.

El proyecto identifica como problema ambiental preexistente el "represamiento de las aguas superficiales por efecto dique ocasionado por las infraestructurales viales influye no solo en el volumen del agua superficial, sino también en el nivel del agua subterránea y en la humedad y capacidad de uso de los suelos"; "En zona urbana y peri-urbana de la ciudad de Pilar, las calles que interceptarían la vía proyectada no disponen de un sistema de drenaje adecuado de las aguas pluviales, las canalizaciones existentes y obras de arte 
del tipo alcantarillas y puentes son insuficientes y se encuentran en su mayoría obstruidas por sedimentación con material árido y residuos sólidos de tipo domiciliario. Esta situación impide el libre encauzamiento de las aguas de escorrentías. (RIMA, pág. 25). Según refiere el mismo documento (RIMA, pág. 30), la ventaja que ofrece las alcantarillas celulares es facilitar los trabajos de limpieza de las secciones hidráulicas, el retiro y remoción de sedimentos y vegetación que obstruyan el curso natural de las aguas, evitando de esta manera el represamiento de las mismas.

Otro proyecto que se consideran fundamentales por su envergadura en impacto es El proyecto "Revisión de la obra existente, estudio y elaboración de alternativas de solución definitiva de defensa costera de la ciudad de Pilar". En informe ejecutivo del estudio técnico de Revisión de obra existente, estudio y elaboración de alternativas de solución definitiva de defensa costera, se utilizó una simulación en aparato digital complementados con cálculos, los cuales indican que son necesarios los reservorios de acumulación por los siguientes motivos fundamentales: "Regular y atenuar los caudales máximos, disminuyendo los mismos con Estaciones de bombeo y de diseño de Alcantarillas.", "Permiten almacenar la precipitación caída en recinto protegido, sin necesidad de iniciar el bombeo inmediatamente. Esto, en el caso de lluvias intensas." (MOPC , 2017). La propuesta cuenta con un Estudio de Impacto Ambiental preliminar, que concluye destacando la “...necesidad de ordenar el suelo urbano en todos sus aspectos y principalmente en relación al desagüe pluvia que causa problemas de inundación en varios puntos de la ciudad luego de una precipitación significativa..." La alternativa de solución presentada contempla en gran medida las variables que afectan a los cauces urbanos y podría contribuir a la mitigación a los problemas ambientales que actualmente soporta la ciudad, además de dar respuestas al recurrente problema de inundación de la ciudad. A pesar de contarse con este estudio técnico, no se consideró para los proyectos Otro importante estudio técnico es el aportado por la Universidad Nacional de Pilar. A través del Instituto de Bioecología e Investigación Subtropical, ha presentado la 3ra. Edición del Mapa Hipsométrico del Casco Céntrico de la Ciudad de Pilar, que muestra los niveles o cotas de riesgo en los diferentes barrios de Pilar. Además, en los laboratorios de la Universidad se analizan las aguas desde el punto de vista físico, químico y microbiológico, lo que aporta conocimiento acabado sobre la turbidez, la dureza, el $\mathrm{pH}$, la presencia de nitritos, materiales pesados, la presencia de bacterias patógenas, entre 
otras. Se dispone de suficientes estudios técnicos que pueden servir de antecedentes para generar proyectos de disposiciones legales.

\section{CONCLUSIÓN O CONSIDERACIONES FINALES}

Se evidencia insuficiente coordinación interinstitucional, ya que las diversas obras encaradas se realizaron sin contemplar el complejo sistema de cuencas hídricas del Ñeembucú, en el que está inserto Pilar. En ocasiones, se adoptan medidas correctivas por falta de previsión, como, por ejemplo, la de aumentar las alcantarillas en el trayecto de la ruta de circunvalación, actualmente en construcción, que todavía no concluye y la causa problemas de drenaje de las aguas por efecto dique.

La Municipalidad de Pilar no cuenta con un Plan de Ordenamiento Urbano y Territorial, donde se establezca una reglamentación del uso del suelo, disposición final de residuos y gestión integral de los recursos hídricos, así como otras cuestiones que reduzcan los riesgos de desastre, propios de los ámbitos urbanos, considerando su proyección de crecimiento.

En coincidencia con lo concluido en la Mesa Social Ambiental (2013), se afirma que, en materia de protección legal ambiental, faltan aún algunas adecuaciones al marco jurídico, particularmente en lo referido al desarrollo de mejores incentivos e instrumentos económicos para la conservación, pero el gran problema sigue siendo la muy limitada capacidad de las instituciones para hacer cumplir efectivamente lo estipulado en las leyes ambientales.

A más de declarar de Interés Ambiental Nacional los humedales del pantanal del departamento de Ñeembucú, la SEAM no dispone de instrumentos legales que regulen la gestión integral de los recursos hídricos de la cuenca urbana de Pilar. Es imperante contar con instrumentos legales que protejan efectivamente los cauces hídricos de toda actividad humana que lo afecte. Las instituciones responsables de dictar disposiciones legales deben cumplir con las exigencias de la Constitución Nacional y compromisos asumidos en los Convenios ratificados, así como los mandatos de sus propias leyes de creación. Puntualmente, se requiere modificar la Ley No 3239/2007 de Recursos Hídricos, de modo a establecer restricciones que garanticen la conservación y manejo de humedales El municipio debe ordenar y controlar el crecimiento urbano e implementar la vigilancia ambiental, control y aplicación de penalizaciones. Se requiere que las disposiciones 
legales locales se funden en un estudio acabado de las condiciones hidrológicas e hidráulicas de los causes urbanos naturales de la ciudad de Pilar.

Es necesario que todos los actores sociales e institucionales se involucren en la realización de un estudio que abarque todas las variables de impacto sobre las cuencas hídricas, tomando como antecedente los estudios técnicos dispersos. La SEAM, la Gobernación y los municipios, a través de sus respectivos departamentos, deben potenciar el sentido de responsabilidad compartida hacia el entorno y coordinar sus acciones en la búsqueda de la protección y conservación de humedales urbanos de la ciudad de Pilar.

\section{LISTA DE REFERENCIAS}

Bertoni, Juan Carlos. Maza, Jorge (2014) Aspectos asociados a las inundaciones urbanas en Argentina. Material extraído del Libro: Inundaciones Urbanas en Argentina., Bertoni, J.C. (org.) (2004).

Chamorro, Liza (2017). Determinação dos parâmetros morfometricos da bacia urbana da cidade de Pilar - Paraguay, com a aplicação das ferramentas de geoprocessamento em Arcgis 10.2.2. Facultad de Ingeniería. UNA.

Chocat, B. (1997). Aménagement urbain et hydrologie, La Houille Blanche, № 7, 12-18. Consejo Nacional del Ambiente, Resolución N. ${ }^{\circ} 04$ de fecha 31 de mayo de 2005 Por la que se aprueba la Política Ambiental Nacional del Paraguay (PAN). Disponible en: http://www.seam.gov.py/gestiones-de-la-seam/politica-ambiental-nacional

Dirección Nacional de Aeronáutica Civil. Dirección de Meteorología e Hidrología. http://www.meteorologia.gov.py/

Dipecho, América del Sur 2011 - 2012. Guía metodológica para la sistematización de herramientas para la gestión de riesgo (Noviembre, 2011)

Inserción de Paraguay en el Mundo Diagnóstico y Lineamientos. Mesa Social Ambiental.

Serie Notas de Política realizadas en el marco de la plataforma de organizaciones Paraguay Debate. Diálogo de Políticas N 9. Marzo de 2013.-

Mapa Hipsométrico del casco céntrico de la Ciudad de Pilar. Disponible en: http://unp.edu.py/presentacion-de-la-3ra-edicion-del-mapa-hipsometrico-del-cascocentrico-de-pilar/

Mapas del casco céntrico de la Ciudad de Pilar y su Estado de Riego. Disponible en: http://unp.edu.py/presentacion-de-la-3ra-edicion-del-mapa-hipsometrico-del-cascocentrico-de-pilar/ 
Memorias del Segundo Encuentro Internacional de Derecho Ambiental. Secretaría de Medio Ambiente y Recursos Naturales. Instituto Nacional de Ecología. Programa de las Naciones Unidas para el Medio Ambiente. 2004.

Plan de Desarrollo Sustentable Pilar. 2016. Consejo de Desarrollo Municipal. Municipalidad de Pilar. http://pilar.gov.py/wp-content/uploads/2016/10/PLANDESARROLLO-PILAR-TERMINADO.pdf

SEAM. Relatorio de Impacto Ambiental - Proyecto Estudios de Ingeniería para el Acceso Vial al Puerto de Pilar. Departamento del Ñeembucú, 2014.

SEAM. Relatorio de Impacto Ambiental (RIMA) presentado por la Inmobiliaria Don Quintín S.A. para el proyecto de loteamiento de lugar denominado Laguna Gadea. Pilar, Neembucú. 2016.

SEAM. Relatorio de Impacto Ambiental Proyecto "Revisión de la obra existente, estudio y elaboración de alternativas de solución definitiva de Defensa Costera de la Ciudad de Pilar”. Pilar Ñeembucú 2017.

UNESCO (2014). Qué son los Caudales Ambientales y cuál es la perspectiva de su aplicación en Uruguay. Documentos Técnicos del PHI-LAC, $N^{\circ} 34$. Programa Hidrológico Internacional para América Latina y el Caribe (PHI-LAC) Oficina Regional de Ciencia para América Latina y el Caribe.

Viand, J., González, G. (2017) Crear riesgo, ocultar riesgo: gestión de inundaciones y política urbana en dos ciudades argentinas. Programa de Investigaciones en Recursos Naturales y Ambiente (PIRNA), Instituto de Geografía, Facultad de Filosofía y Letras, Universidad de Buenos Aires.

Constitución Nacional del Paraguay (1992). Disponible en: https://www.pj.gov.py/ebook/libros_files/Comentario_a_la\%20Constitucion_\%20T omo_IV.pdf

Ley No 350/94 "Que aprueba la convención relativa a los humedales de importancia internacional, especialmente como hábitat de aves acuáticas”. Convención Ramsar. Disponible en: http://www.seam.gov.py/

Ley No 294/93 “De Evaluación de Impacto Ambiental” y el Decreto No 453/2013.

Ley $\quad \mathrm{N}^{\circ} \quad 1.160 / 97 . \quad$ "Código Penal Paraguayo".
http://www.mre.gov.py/v1/Adjuntos/Privacidad/Ley1160.pdf 
Ley $\mathrm{N}^{\mathrm{o}} 1.561 / 00$ - Crea el Sistema Nacional del Ambiente, el Consejo Nacional del Ambiente y la Secretaría del Ambiente

Ley N 426/94 Que establece la Carta Orgánica del Gobierno Departamental

Ley No 3239/2007 “De Los Recursos Hídricos del Paraguay”;

Ley N³966/10 Ley Orgánica Municipal.

Ley N 1183/85 Código Civil Paraguayo.

Resolución N ${ }^{\circ}$ 145/2005 Por la cual se Promulga por Sanción Ficta la Ordenanza que establece el "Código de Edificación de la ciudad de Pilar".

Resolución SEAM 170/06 "Por la Cual se aprueba la reglamentación del Consejo de Aguas por Cuencas Hídricas". 